\title{
Design of a Traction Motor With Tooth-Coil Windings and Embedded Magnets
}

\author{
Pia Lindh, Member, IEEE, Juho Montonen, Paula Immonen, Juan A. Tapia, Member, IEEE, and \\ Juha Pyrhönen, Member, IEEE
}

\begin{abstract}
Traction motor design significantly differs from industrial machine design. The starting point is the load cycle instead of the steady-state rated operation point. The speed of the motor varies from zero to very high speeds. At low speeds, heavy overloading is used for starting, and the field-weakening region also plays an important role. Finding a suitable fieldweakening point is one of the important design targets. At the lowest speeds, a high torque output is desired, and all current reserves of the supplying converter unit are used to achieve the torque. In this paper, a 110-kW 2.5-p.u. starting torque and a maximum 2.5-p.u. speed permanent-magnet traction motor will be studied. The field-weakening point is altered by varying the number of winding turns of machine. One design is selected for prototyping. Theoretical results are verified by measurements.
\end{abstract}

Index Terms-Inductance, permanent-magnet machines, traction motors.

\section{NOMENCLATURE}

$A \quad$ Linear current density.

$B \quad$ Flux density.

$E_{\mathrm{PM}} \quad$ Permanent-magnet induced voltage.

$f \quad$ Frequency.

$h_{\mathrm{PM}} \quad$ Height of the permanent magnet.

$k_{\mathrm{w}} \quad$ Winding factor of the working harmonic.

$l \quad$ Physical length.

$l^{\prime} \quad$ Effective length.

$L_{\mathrm{d}}, L_{\mathrm{q}} \quad \mathrm{d}$ - and q-axis synchronous inductance.

$L_{\mathrm{m}} \quad$ Magnetizing inductance.

$L_{\delta} \quad$ Air gap leakage inductance.

$m \quad$ Number of phases.

$n \quad$ Rotational speed.

$N_{\text {ph }} \quad$ Number of coil turns in a phase.

$p \quad$ Number of pole pairs.

$q \quad$ Slots per pole and phase.

$T$ Torque.

$U_{\mathrm{ph}} \quad$ Supply voltage.

$V_{\mathrm{r}} \quad$ Rotor volume.

$\zeta \quad$ Angle between distribution of B and A.

Manuscript received February 28, 2013; revised June 10, 2013; accepted August 4, 2013. Date of publication August 21, 2013; date of current version February 7, 2014.

P. Lindh, J. Montonen, P. Immonen, and J. Pyrhönen are with the Department of Electrical Engineering, Lappeenranta University of Technology, 53851 Lappeenranta, Finland (e-mail: pia.lindh@lut.fi; juho.montonen@lut.fi; paula.immonen@lut.fi; juha.pyrhonen@lut.fi).

J. A. Tapia is with the Department of Electrical Engineering, University of Concepción, 3349001 Concepción, Chile (e-mail: juantapia@udec.cl).

Color versions of one or more of the figures in this paper are available online at http://ieeexplore.ieee.org.

Digital Object Identifier 10.1109/TIE.2013.2279126

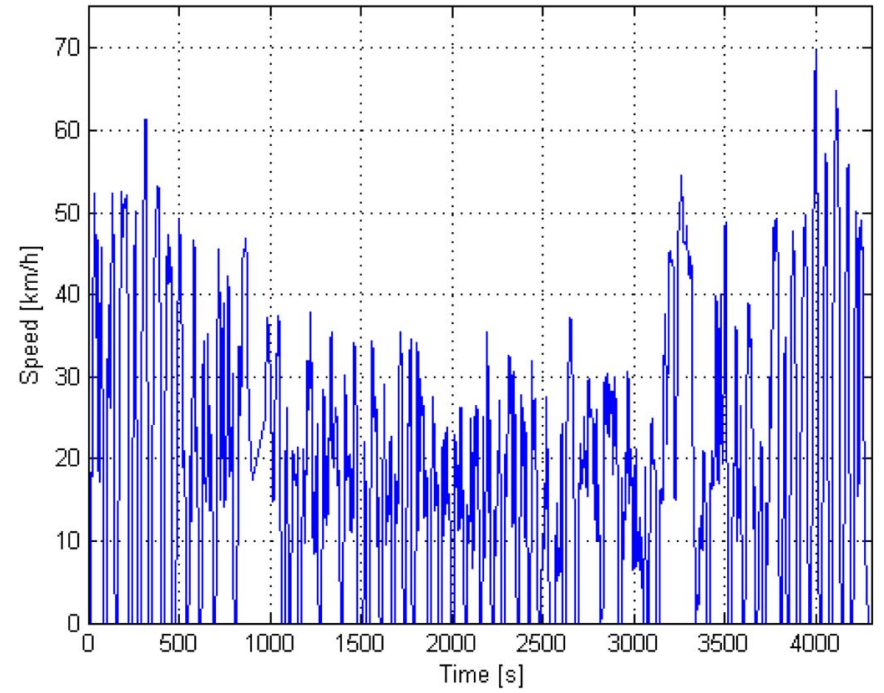

Fig. 1. Speed profile of the line 85 bus in Gothenburg.

$\delta \quad$ Physical air gap.

$\delta_{\text {eff }} \quad$ Effective air gap.

$\delta_{\mathrm{s}} \quad$ Load angle.

$\mu_{0} \quad$ Permeability of vacuum.

$\sigma \quad$ Tangential stress.

$\sigma_{\delta} \quad$ Leakage factor.

$\tau_{\mathrm{p}} \quad$ Pole pitch.

$\tau_{\mathrm{u}} \quad$ Slot pitch.

$\varphi \quad$ Power factor angle.

$\Phi_{\mathrm{PM}} \quad$ Permanent-magnet flux.

$\omega \quad$ Electrical angular frequency.

\section{INTRODUCTION}

I $\mathrm{N}$ TRACTION applications, a certain starting torque and certain operating speed range are given as initial design parameters. The load of a traction motor constantly varies. Publicly available data on the speed profile of the line 85 bus in Gothenburg are given as an example (see Fig. 1).

By applying the final drive ratio of $1: 7.01$ and the 1-m wheel diameter of the bus, the speed profile for a lightweight bus was analyzed. In the study, $\pm 1700-\mathrm{Nm}$ peak torque was set as the machine design target. The average root mean square (RMS) torque during the operating cycle is about $500 \mathrm{Nm}$. Therefore, the machine should be capable of cooling when operated at this RMS torque. At the rated speed, this torque corresponds to an output power of $80 \mathrm{~kW}$.

The high torque at the lowest speed area needs specialized control to maximize the torque per ampere. A traction motor 
should normally be capable of achieving at least 2-3-p.u. torque at the start [1], [2]. In our example case, the 500-Nm RMS torque and $1700-\mathrm{Nm}$ peak torque result in the need of about $3.4 T_{\mathrm{n}}$ peak torque.

The per-unit system used in this paper is based on the rated converter voltage of $400 \mathrm{~V}$ corresponding to 1-p.u. voltage. The 1-p.u. rated current corresponds to the rated power of the machine. The 1-p.u. rated speed is selected to $1500 \mathrm{r} / \mathrm{min}$.

The power and voltage levels of the power electronic unit usually determine the maximum current available. In addition, the battery overload limits the power and thereby decides the maximum current. Therefore, the maximum current available is also one of the design process parameters.

Traction motors should produce torque both by the permanent-magnet flux and by the reluctance difference. Toothcoil machines are not optimal in producing reluctance torque; however, as in integral-slot machines, the reluctance difference can be also utilized in tooth-coil machines. For such a permanent-magnet synchronous motor (PMSM), the maximum torque per ampere can always be found; however, naturally, saturation, including cross-saturation, at the highest torques heavily affects the selection of the correct current angle. Rotor surface magnet machines and machines with embedded magnets equipped with fractional slot windings for hybrid traction application have been studied, e.g., in [3] and [4]. Traction motor design has been previously studied, e.g., in [5].

The target in this study is to use tooth-coil (fractional slot, concentrated, and nonoverlapping) windings leading to costefficient armature manufacturability due to a smaller amount of copper than with integral-slot windings [6], [7]. With integralslot windings, the maximum torque is expected to be slightly higher with the similar rotor volume as it was presented by Salminen et al. in [9]. Tooth-coil PMSMs offer different values of leakage inductance, which can be utilized in trying to realize a "constant power" operating curve of a PMSM. In [8], Ponomarev et al. focused on the air gap leakage inductance of tooth-coil machines. The air-gap leakage can be the dominating component in the synchronous inductance. By selecting a large synchronous inductance, it is easy to enter deep in the field weakening. This paper continues the previous work reported in [10], presents the details of the prototype machine, and provides measurement results to validate the calculation process.

\section{Design Process of A Traction Motor}

The main boundary condition for the electromagnetic design is set by the value of the tangential stress applied in the machine [11]. Different types of electrical machines have different acceptable stress ranges for proper operation, and the stress can be increased if cooling is improved unless machine inductances limit the torque. The relation between the linear current density fundamental peak value $\hat{A}$ and the air gap flux density fundamental peak value $\hat{B}$ and the angle between the $B$ and $A$ distribution fundamentals $\zeta$ (often close to the angle $\varphi$ of the power factor $\cos \varphi$ ) define the tangential stress as

$$
\sigma \approx \frac{1}{2} \hat{A} \hat{B} \cos \zeta
$$

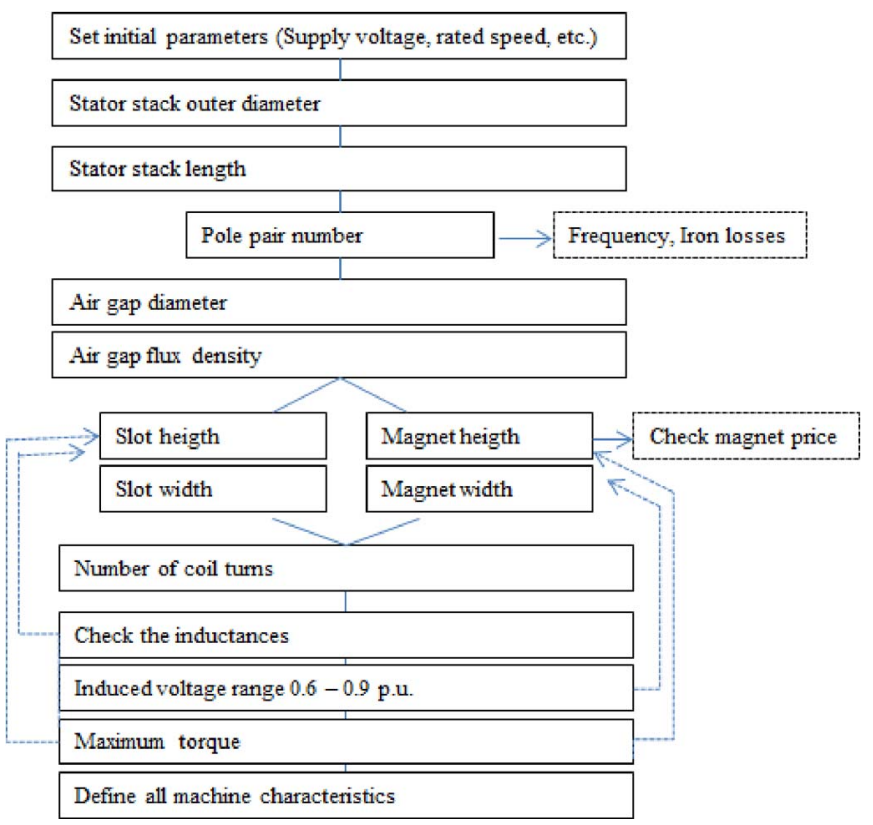

Fig. 2. Motor design process chart.

The values for the linear current density are initially chosen according to the cooling method. For this study, the stator indirect water-cooling method has been selected; therefore, the linear current density for a $110-\mathrm{kW} 1500-\mathrm{min}^{-1} \mathrm{PM}$ motor should vary from 90 to $150 \mathrm{kA} / \mathrm{m}$. The current density range would be from 4 to $6 \mathrm{~A} / \mathrm{mm}^{2}$. Tooth-coil machines are easier to cool than corresponding integral-slot machines. This is because of the low proportion of the end winding length compared with the slot-bound windings. End windings are usually the hottest components in a motor. In this case, the upper limit of the recommended current density was even exceeded as the rated current density of $6.5 \mathrm{~A} / \mathrm{mm}^{2}$ was chosen for the rated torque. At low-speed area, there will be higher current densities for a short start-up time, but this transient may be assumed to be only a few seconds during acceleration of the traction drive. The electromagnetic torque $T$ of rotor volume $V_{\mathrm{r}}$ may be solved as

$$
T=2 \sigma V_{\mathrm{r}} .
$$

In machine design, there is a considerable number of free parameters to be solved, when aiming at an optimal solution. Fortunately, some parameters are fixed by the application, e.g., the supply voltage level. The motor design process chart is presented in Fig. 2. It follows the procedure explained in [11]. In our case, the standard frame size was used as the outer diameter boundary. The length of the machine was adjusted so that the torque and inductances are preferable.

In case of tooth-coil-wound machines (where $q$ is less than or equal to 0.5 ), the leakage inductance is dominating, and the pull-out torque is roughly proportional to the number of stator slots per pole and per phase $q$ [9]. High pull-out torques are expected with machines in which $q$ is equal to 0.5 according to [9]. Several motors were designed with different pole pair numbers. $p=4,6,8$ and 12 (with $q=0.5$ ) in the same frame size. According to parameters in Table I, the best number of pole pairs was 8 , when considering the manufacturability of magnets (practical geometry) as well as the operating frequency (having an effect 
TABLE I

Pole PAir Numbers AND Slot Numbers

\begin{tabular}{ccccc}
\hline \hline Slots per pole and phase, $q$ & 0.5 & 0.5 & 0.5 & 0.5 \\
\hline Number of stator slots, $Q_{\mathrm{s}}$ & 12 & 18 & 24 & 36 \\
Pole pair number, $p$ & 4 & 6 & 8 & 12 \\
Supply frequency at $1500 \mathrm{~min}^{-1}$ & 100 & 150 & 200 & 300 \\
Supply frequency at $3000 \mathrm{~min}^{-1}$ & 200 & 300 & 400 & 600 \\
Slot pitch, mm & 113 & 76 & 57 & 38 \\
Pole pitch, $\mathrm{mm}$ & 130 & 86 & 65 & 43 \\
\hline
\end{tabular}

TABLE II

MACHINE PARAMETERS

\begin{tabular}{|c|c|c|c|c|}
\hline Slots per pole and phase, $q$ & \multicolumn{4}{|c|}{0.5} \\
\hline Stator slots & \multicolumn{4}{|c|}{24} \\
\hline Poles & \multicolumn{4}{|c|}{16} \\
\hline Permanent magnet flux $\Phi_{\mathrm{PM}}[\mathrm{mVs}]$ & \multicolumn{4}{|c|}{5.3} \\
\hline Length of the stator stack [mm] & \multicolumn{4}{|c|}{190} \\
\hline Stator outer diameter $[\mathrm{mm}]$ & \multicolumn{4}{|c|}{430} \\
\hline Stator inner diameter $[\mathrm{mm}]$ & \multicolumn{4}{|c|}{330} \\
\hline Number of coil turns in phase $N_{\mathrm{ph}}$ & 56 & 64 & 72 & 80 \\
\hline
\end{tabular}

to iron losses). Manufacturability costs would be smaller with a low number of slots and poles, but a magnet width of $130 \mathrm{~mm}$ would be difficult to handle. In addition, a large amount of slots was preferred due to the heat transfer (the heat-transferring area from slots is larger with a larger amount of slots).

Next, some stator parameters and the permanent-magnet amount are selected to make motor comparison feasible. The motor versions studied will have similar stator geometry, and the amount of the permanent-magnet material was fixed to $8.2 \mathrm{~kg}$ during the design process. The total mass of the motor is $250 \mathrm{~kg}$. The length and stator diameters are defined according to the application in which machine is used and are shown in Table II.

The amount of permanent magnets is fixed, leading to a certain value of permanent-magnet flux $\Phi_{\mathrm{PM}}$. Neglecting the temperature dependence of the polarization, permanent-magnet flux $\Phi_{\mathrm{PM}}$ can be kept constant, and induced voltage $E_{\mathrm{PM}}$, therefore, linearly increases with the speed, as can be seen from

$$
E_{\mathrm{PM}}=k_{\mathrm{w}} \omega N_{\mathrm{ph}} \Phi_{\mathrm{PM}} / \sqrt{2}
$$

in which $k_{\mathrm{w}}$ is the winding factor for the working harmonic, $\omega$ is the electrical angular frequency ( $\omega=2 \pi f, f$ is electrical frequency), and $N_{\mathrm{ph}}$ is the amount of coil turns in series of the stator phase. The d-axis magnetizing inductance may be solved as [11]

$$
L_{\mathrm{md}}=\frac{2 m \mu_{0}}{\pi} \frac{\tau_{\mathrm{p}}}{p \pi \delta_{\mathrm{eff}}} l^{\prime}\left(k_{\mathrm{w}} N_{\mathrm{ph}}\right)^{2}
$$

where $\mu_{0}$ is the permeability of the vacuum, $\tau_{\mathrm{p}}$ is the pole pitch, $l^{\prime}$ is the effective length of the stator core, and $\delta_{\text {eff }}$ is the effective air gap (in machines without cooling passages and axially long magnets $l^{\prime} \approx l+2 \delta$, where $l$ is the physical length of the stator core, and $\delta$ is the physical length of the air gap) [11]. From (4), one may notice that increasing the number of the winding turns results in fast increasing magnetizing inductance. The leakage inductance is also proportional to $N_{\mathrm{ph}}^{2}$.

The torque developed can be solved for a salient pole machine with per-unit values as

$$
T=\frac{3 p}{4 \pi^{2} n^{2}}\left(\frac{U_{\mathrm{ph}} E_{\mathrm{PM}}}{L_{\mathrm{d}}} \sin \delta_{\mathrm{s}}+U_{\mathrm{ph}}^{2} \frac{L_{\mathrm{d}}-L_{\mathrm{q}}}{2 L_{\mathrm{d}} L_{\mathrm{q}}} \sin 2 \delta_{\mathrm{s}}\right)
$$

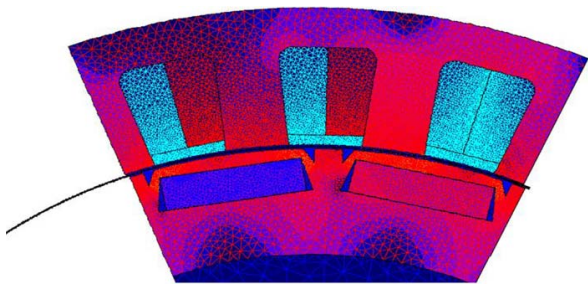

Fig. 3. Tooth-coil winding three-phase motor having 24 slots and 16 poles $(q=0.5)$. The magnet-retaining lamination layer also offers a tangential path for the main flux to efficiently travel to the narrow teeth.

in which $p$ is the pole pair number, $n$ is the rotational speed in $\mathrm{s}^{-1}, L_{\mathrm{d}}$ is the d-axis synchronous inductance, $L_{\mathrm{q}}$ is the q-axis synchronous inductance, and $\delta_{\mathrm{s}}$ is the load angle. In traction use, supply phase voltage $U_{\mathrm{ph}}$ will be varied by the control unit, and induced phase voltage $E_{\mathrm{PM}}$ varies according to the speed.

The maximum torque that can be delivered by a certain motor with a certain maximum current can be increased by increasing the amount of winding turns while keeping the current constant. This results in both increased linear current density $A$ and synchronous inductance. These will result in different fieldweakening points.

Four different-winding-arrangement similar-volume 110-kW $1500-\mathrm{min}^{-1}$ traction-motor designs are reported next. These motors should give at least 2.5-p.u. torque at low speed and at least approximately 0.5 p.u. at double speed as the rated speed is fixed to $1500 \mathrm{~min}^{-1}$. Analytical calculations were based on the machine's d- and q-axes model and the vector presentation. The results are verified by finite-element analysis (FEA), utilizing Cedrat's Flux2D. Interior permanent magnets were utilized in the rotor, as depicted in Fig. 3. The motor is designed to have maximum no-load flux densities of teeth, yoke, and iron bridge $1.5,1.3$, and $2.2 \mathrm{~T}$, respectively. The permanent-magnet width is $45 \mathrm{~mm}$, the height is $12 \mathrm{~mm}$, and the stack length is $190 \mathrm{~mm}$, resulting in permanent-magnet flux of $5.3 \mathrm{mVs}$. The permanentmagnet material has a remanent flux density of $1.15 \mathrm{~T}$, a relative permeability of 1.05 , and a coercive force of $980 \mathrm{kA} / \mathrm{m}$. The isotropic resistivity of the permanent magnet is set to $1.5 \times 10^{-6} \Omega \cdot \mathrm{m}$. The steel material used is M270-35A.

With $q=0.5$, the air gap leakage inductance $L_{\delta}=\sigma_{\delta} L_{\mathrm{m}}$ is $0.46 L_{\mathrm{m}}$, resulting in a moderate synchronous inductance $L_{\mathrm{d}}$. Such a value is acceptable in this case when the maximum speed is only twice the rated speed [8]. The machine has embedded magnets, and there is some saliency $\left(L_{\mathrm{q}} / L_{\mathrm{d}}=1.4\right)$; however, the proportion of the reluctance torque is limited because of the small inductance difference. In the rated point operation, the reluctance torque proportion is $5 \%$ with the maximum torque per ampere control.

In machines with no saliency, the direct axis current should be set in practice to nearly zero at the rated speed so that in the field weakening, negative d-axis magnetization can be applied. In machines having inverse saliency $\left(L_{\mathrm{q}}>L_{\mathrm{d}}\right)$, the optimum current will contain a negative d-axis current. Depending on the inductance level in that kind of traction motor designs, it is easy to reach the field weakening. As the permanent-magnet flux is fixed to $5.3 \mathrm{mVs}$, the permanent-magnet flux linkages now depend only on the numbers of coil turns in phase $N_{\mathrm{ph}}$. In this machine size, the applicable values were 56, 64, 72, 


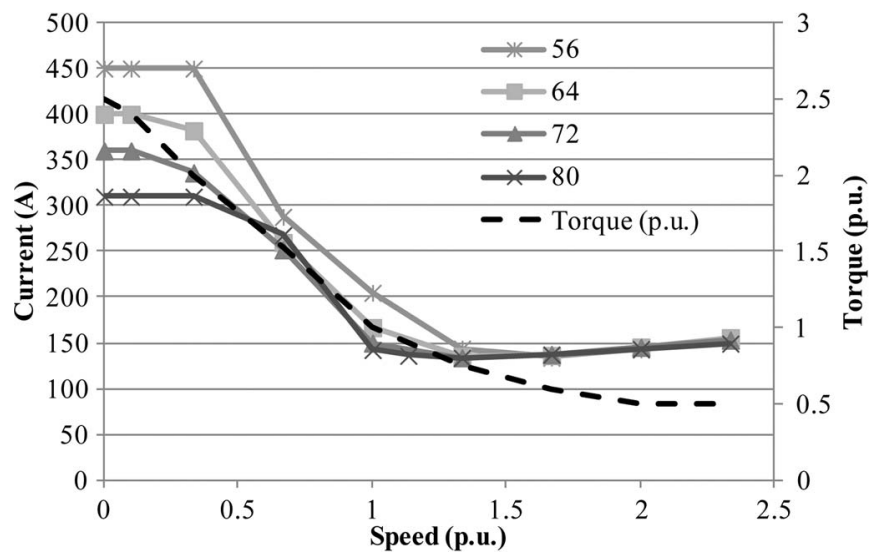

Fig. 4. Target torque and corresponding current demands as functions of speed for motors with $56,64,72$, and 80 winding turns.

and 80 winding turns, leading to $\mathrm{d}$-axis inductance values varying from 0.48 to 0.98 p.u. and q-axis inductance values varying from 0.69 to 1.4 p.u.

\section{NumericAl ANALyses}

As the basis of all computations, the generally known analytical methods and d-q-vector analyses are used. A set of FEAs was performed to evaluate the characteristics of several motor designs. Static finite-element computations were performed to discover the maximum torques. In the dynamic computation, voltage sources were placed to the circuit model, and timestepping analyses were performed with several rotor angles. The eddy current losses in permanent magnets and iron losses were computed over one time period (after the dynamic state had stabilized) to gain accurate results.

In all cases, the supply voltage of $500 \mathrm{~V}$ at the rated speed is used. A motor with a higher amount of winding turns will, of course, achieve the rated torque with a smaller current (and higher voltage) than a motor with lower amount of winding turns. Such a motor enters the field weakening in an earlier phase than other machines. Therefore, the per-unit rated speed should also vary motor by motor; however, in this case, we use the same 1-p.u. rated speed for all the designs.

The computed current values are depicted in Fig. 4. Each design develops a current minimum in the speed area from 1 to 1.7 p.u. It is advisable to select a motor having its minimum current in the speed area, which is assumed to be mostly used. This leads to a good overall drive efficiency. The current values presented produce the same torque.

Naturally, the motor with 80 winding turns has the lowest current values, and the motor with 56 winding turns has the highest. However, copper losses are highest for the 80-windingturn motor above the 0.5-p.u. speed, as shown in Fig. 5. This is due to the high resistance of the motor with 80 winding turns as the slot dimensions were kept the same.

As the converter current rating defines the converter price, the motor designer favors lower values for the current over the wide speed area, however, keeping in mind the copper losses. A high current causes high losses: copper losses and a high current linkage yields to higher PM losses as tooth-coil winding creates

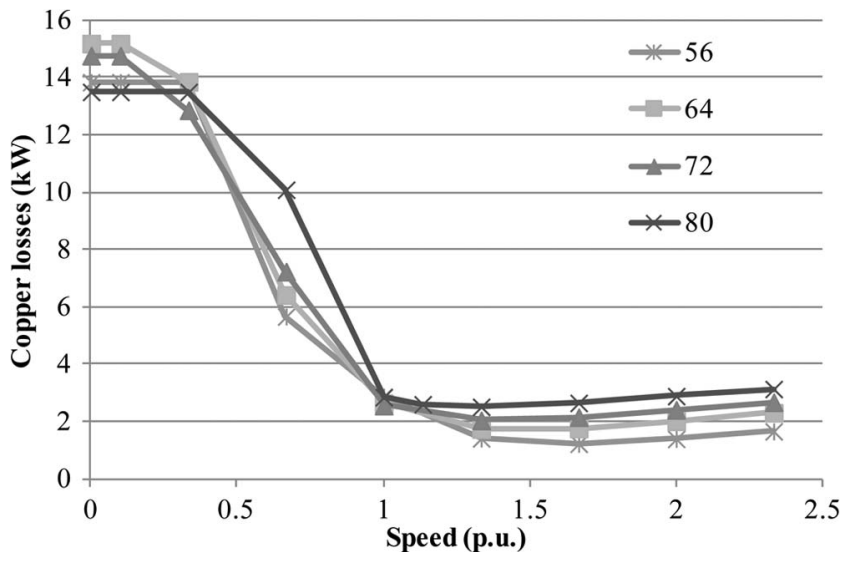

Fig. 5. Copper losses as a function of speed for motors with 56, 64, 72, and 80 winding turns with the currents given in Fig. 4.

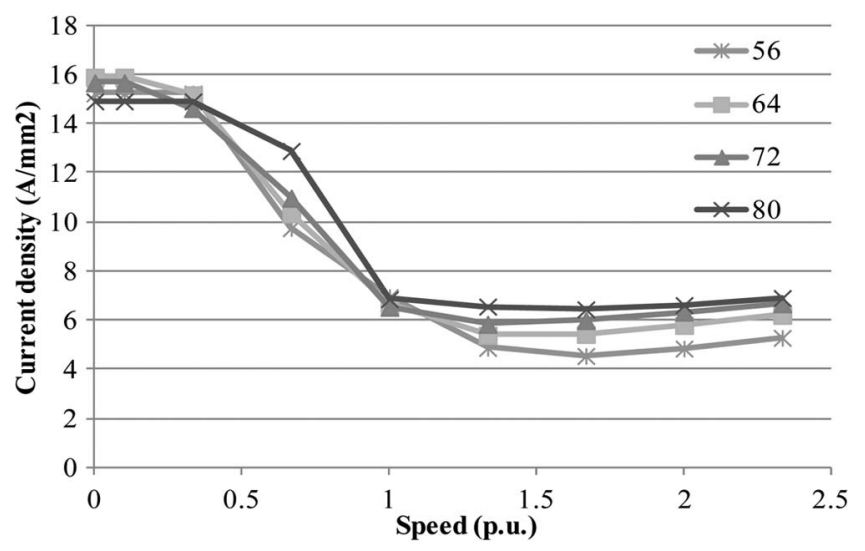

Fig. 6. Current densities in the conductors at different speeds when using the currents given in Fig. 4.

a large amount of spatial harmonics [13]. The current related limitations may be the current density in the conductor or the maximum current that the supply unit can serve. The cooling method of the machine will limit the amount of the current density. Together with minimal end windings, this method allows current density $J$ to be higher than the traditional range from 4 to $6 \mathrm{~A} / \mathrm{mm}^{2}$. The lower values of $J$ are for larger machines and the highest for small machines [11]. As can be seen from the current density values in Fig. 6, there are higher values than $10 \mathrm{~A} / \mathrm{mm}^{2}$ during start up. Although the high torque occurs only at the start during a few seconds, one should carefully look at the duty cycle demand according to the application. The low values are for motors with low values of $N_{\mathrm{ph}}(56,64)$.

In FEAs, the current angles corresponding to the appropriate control were used with acceptable tolerances. The supply circuit has three sinusoidal voltage sources, which were adjusted to reach voltage and current levels close to the desired values corresponding to the maximum torque per ampere control or a suitable field-weakening control.

The losses in the permanent magnets vary according to the speed and current needed. PM eddy current loss values at five different speeds are given in Fig. 7. Even though the magnets are embedded, the losses in segmented magnets are high, and the magnets are sliced into smaller pieces in such machines with tooth-coil windings. Iron losses tend to have some constant value during the field weakening, as seen in Fig. 7. The higher 

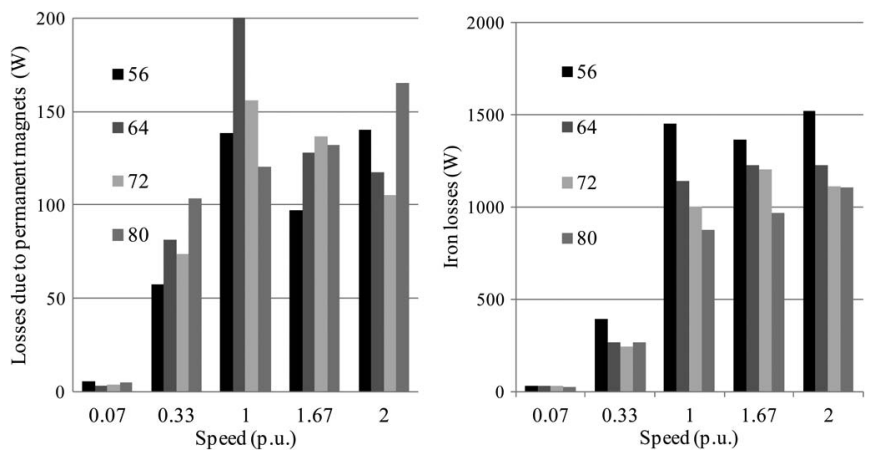

Fig. 7. Losses in permanent magnets and iron losses as a function of speed for motors with 56, 64, 72, and 80 winding turns. FEA results. The magnets have been segmented as the losses would otherwise be too high.

TABLE III

PRototype MACHINE PARAMETERS

\begin{tabular}{cc}
\hline \hline Slots per pole and phase, $q$ & 0.5 \\
\hline Stator slots & 24 \\
Poles & 16 \\
Permanent magnet flux $\Phi_{\mathrm{PM}}[\mathrm{mVs}]$ & 5.3 \\
Length of the stator stack [mm] & 190 \\
Stator outer diameter [mm] & 433 \\
Stator inner diameter [mm] & 330 \\
Number of coil turns in phase $N_{\mathrm{ph}}$ & 56 \\
Induced voltage $E_{\mathrm{PM}}[\mathrm{p} . \mathrm{u}]$ & 0.873 \\
$d$-axis inductance [p.u.] & 0.48 \\
$q$-axis inductance [p.u.] & 0.69 \\
\hline
\end{tabular}

the amount of winding turns is, the lower the iron losses will be at the rated speed and at higher speeds. This is due to a smaller amount of flux density needed at higher speeds in the field weakening.

\section{PRototype Motor}

A $110-\mathrm{kW}$ prototype machine with 24 slots and 16 poles was constructed in order to obtain practical experience concerning the manufacturing of the tooth-coil-wound machine and performance evaluation of a motor using the design procedure proposed. According to the above reasoning, the number of winding turns of one phase was selected to be 56 . Table III summarizes the prototype parameters. The stack length is $190 \mathrm{~mm}$, and the magnet is divided into 19 pieces per pole. Magnet and steel material are the ones presented above.

The synchronous inductance components of the prototype motor are illustrated in Fig. 8. as a function of d- and q-axes currents.

Calculated normal components of the flux density in the air gap at no-load and at the rated load for the design chosen are presented in Fig. 9.

Mechanical computations were also utilized for the prototype motor. The iron parts in the rotor were analyzed with the mechanical finite-element method to fulfill the demands of mechanical strength as the speed reaches $3000 \mathrm{~min}^{-1}$. One optimization was carried out by studying the embedding depth of the magnet. The magnet should be deep enough to avoid PM eddy currents due to stator harmonics, but also not too deep because the efficiency decreases as the permanent magnet embedded deep inside the rotor is leaking its flux heavily. The thickness of the iron bridge above the magnet affects the

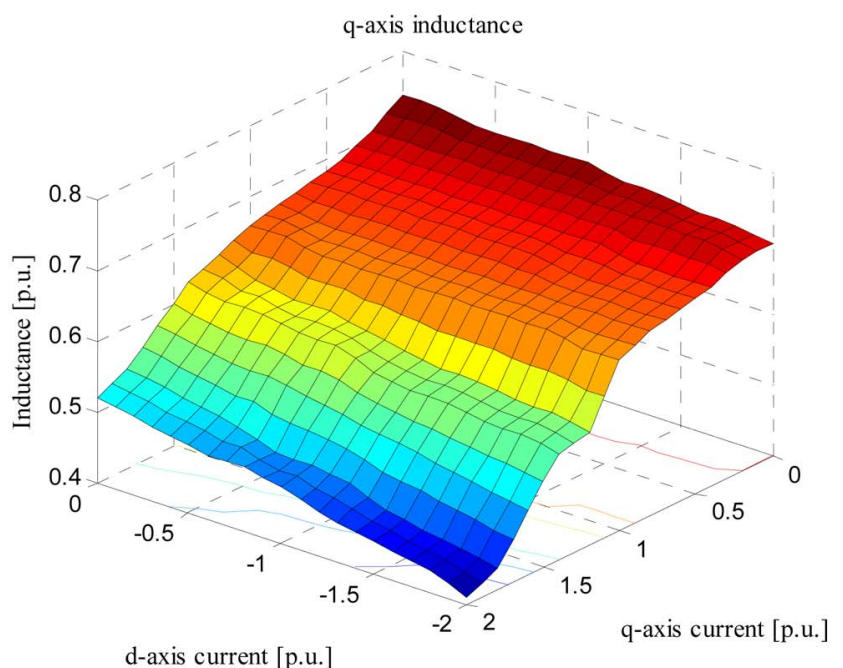

(a)

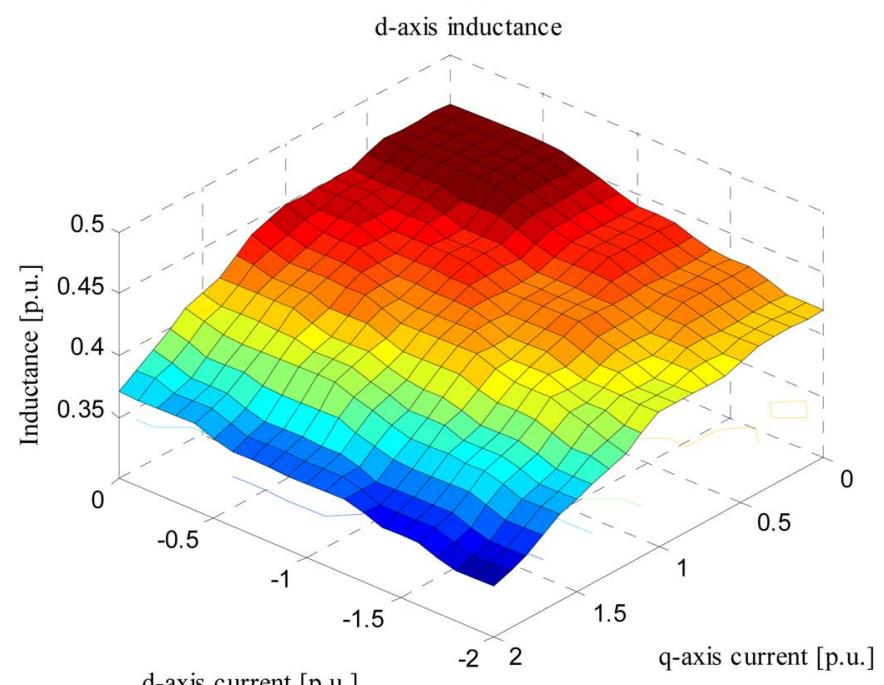

(b)

Fig. 8. Computed synchronous inductances of the prototype motor as a function of $\mathrm{d}$ - and q-axes current of the $110-\mathrm{kW}$ prototype motor. (a) q-axis inductance. (b) d-axis inductance.

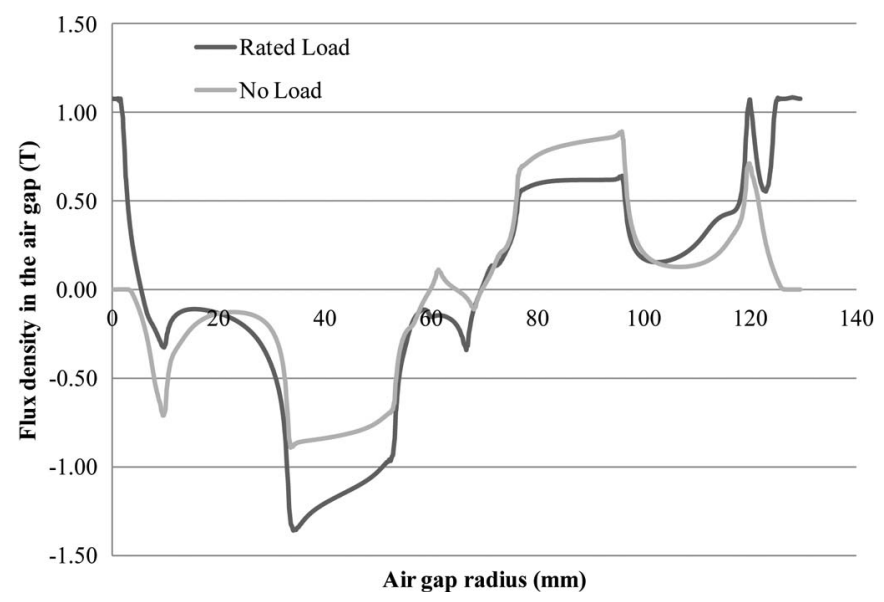

Fig. 9. Flux density normal component in the air gap at no-load and at rated load.

efficiency, as one may see in Fig. 10. The efficiency of the motor is presented as a function of torque with three heights of the iron bridge, i.e., $0.1,0.25$, and 0.5 times the magnet height. 


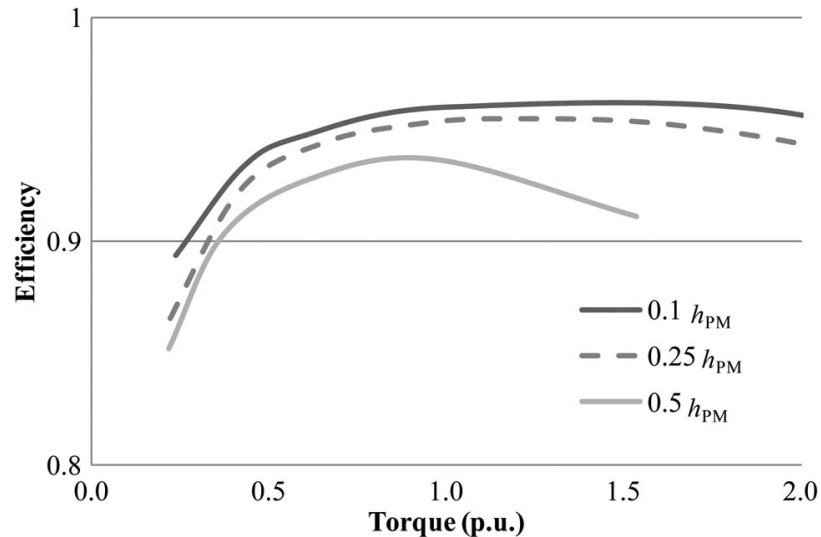

Fig. 10. Efficiency of the motor as a function of torque with three different iron bridge thicknesses, i.e., $0.1,0.25$, and 0.5 times the magnet height.

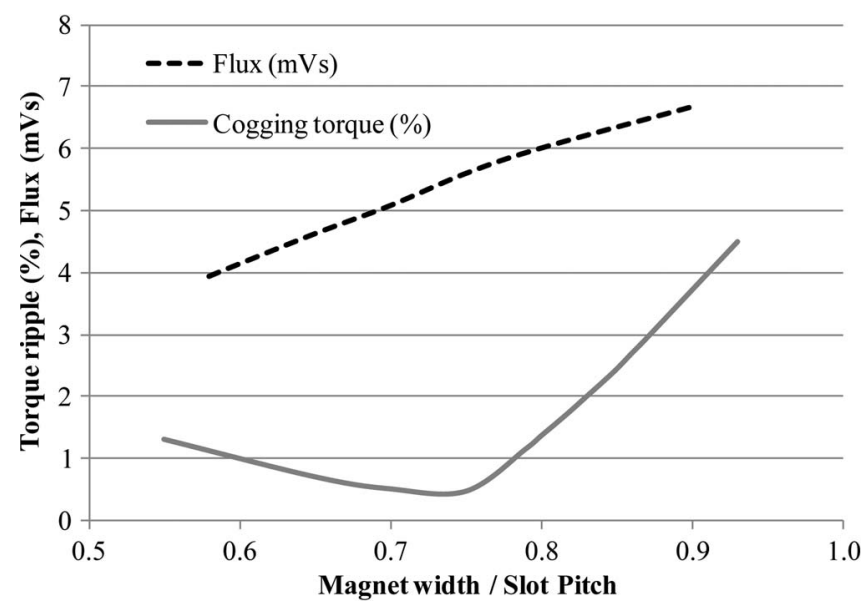

Fig. 11. Flux generated by one embedded magnet and the cogging torque as a function of magnet width to slot pitch.

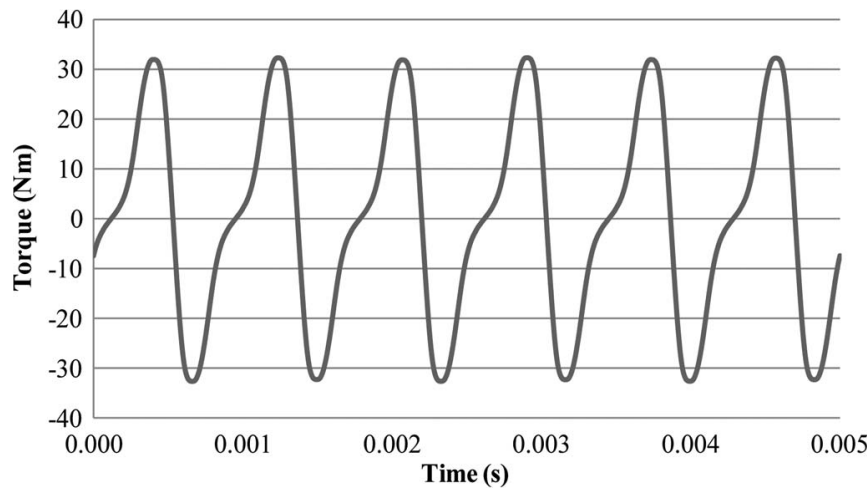

Fig. 12. Cogging torque as a function of time from finite-element computation.

The magnet width was selected in order to have small cogging torque. The flux generated from one embedded magnet is presented in Fig. 11 and the torque ripple as a function of magnet width to slot pitch. Torque ripple is in a very good level as it can also be high in tooth-coil machines [14]. The magnet width of approximately $0.75 \tau_{\mathrm{u}}$ was found to be the optimum and was therefore selected.

The cogging-torque FEA result is depicted in Fig. 12 over one time period, and one may notice the sixth torque harmonics, which are also seen from the spectrum in Fig. 13.

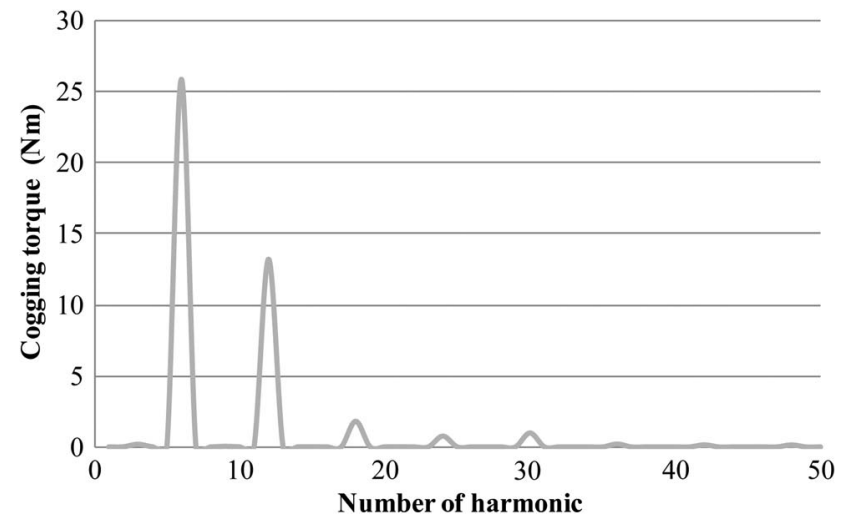

Fig. 13. Cogging-torque spectrum.

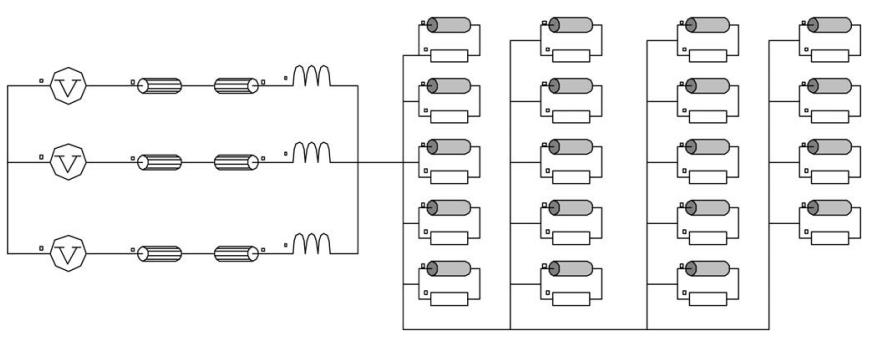

Fig. 14. One magnet pole is split into 19 pieces to accurately compute the PM losses, and each magnet segment is connected to the circuit.

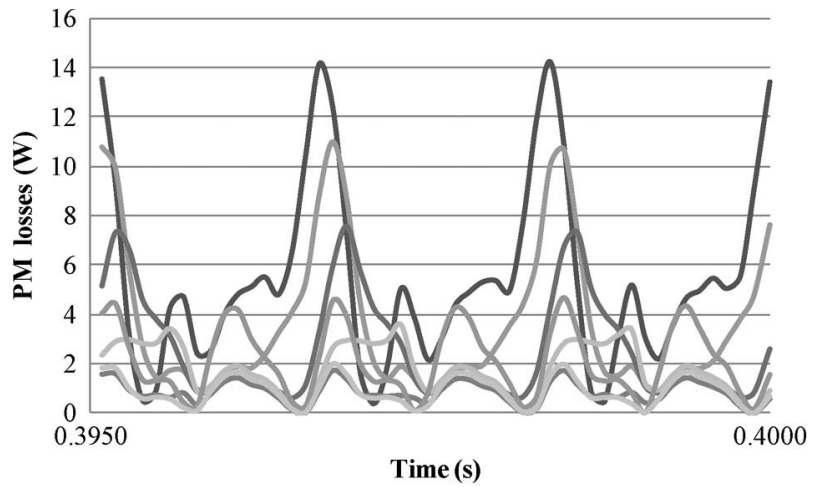

Fig. 15. PM losses of 19 magnet segments.

\section{A. PM Loss Analysis With 2-D FEM}

The finite-element model for a 24-slot 16-pole machine contains two permanent-magnet poles and three slots (each slot carrying two coil sides). Each magnet is segmented into 19 parts, because the prototype motor's magnets were built of 19 permanent-magnet pieces. Each magnet segment is connected to the circuit in Fig. 14 and described as a solid conductor region in order to calculate the losses of all magnet segments. A dynamic computation is carried out, and the losses in each magnet are presented in Fig. 15. The segments in the middle of the magnet and on the magnet edges have different amount of losses, as can be seen in Fig. 15. The RMS value of losses was $20.3 \mathrm{~W}$ on one magnet and $20.9 \mathrm{~W}$ on the other magnet, resulting in 330-W PM loss of the whole machine $(8 \times 41.2 \mathrm{~W})$.

A photograph of the manufactured tooth-coil end winding is provided in Fig. 16. The end windings length in the $\mathrm{N}$-end is only $25 \mathrm{~mm}$. This is a big benefit of tooth-coil machines compared with integral-slot winding machines. 


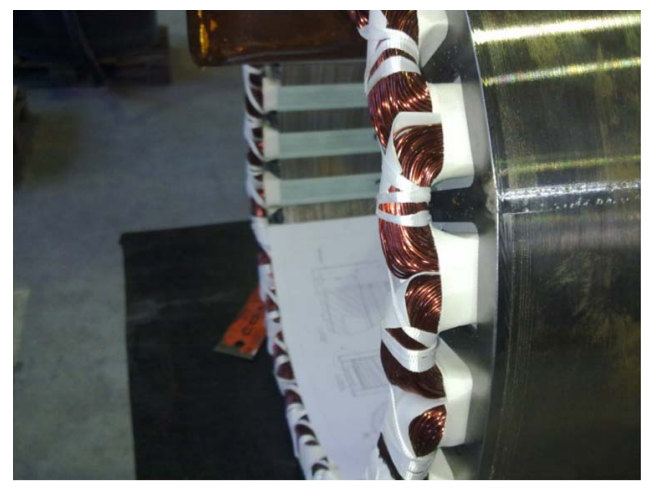

Fig. 16. End windings of the 110-kW prototype motor. The finger plate made of construction steel is also shown. This material was used against instructions because in tooth-coil machines with elevated operating frequency compared with normal $50-\mathrm{Hz}$ machines, the finger plate creates lots of losses unless austenitic material is used.

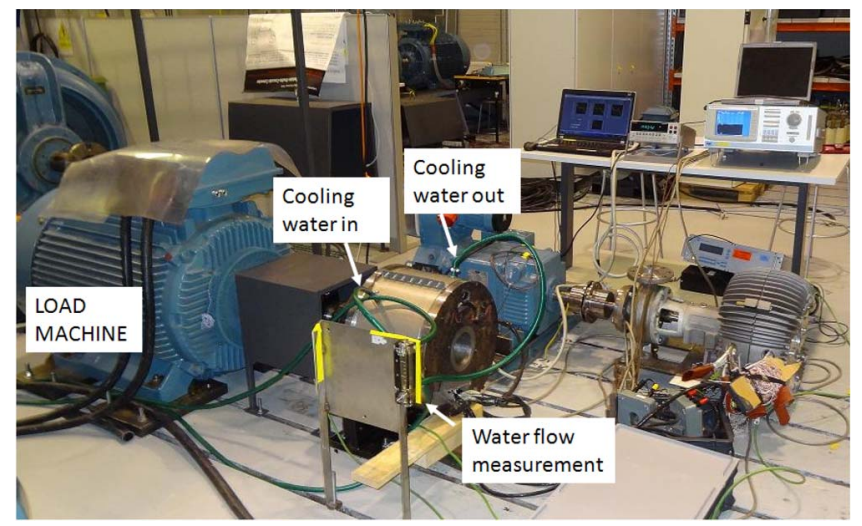

Fig. 17. Prototype machine in the test bench. An indirect water-cooling system with water flow measurement was utilized.

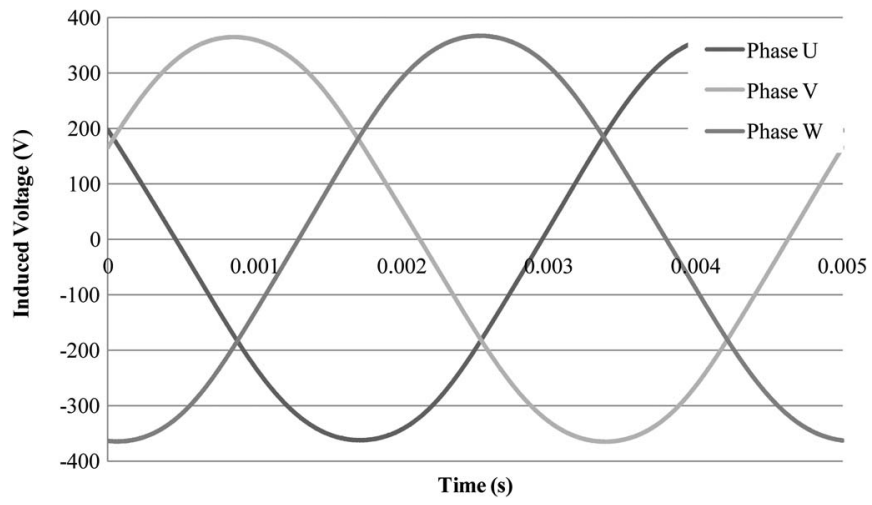

Fig. 18. Induced phase voltages as the machine is warm (end winding temperatures $90{ }^{\circ} \mathrm{C}$ ).

Furthermore, the measurement results provide essential information needed to verify both the analytical calculations and the computations made with the 2-D FEA. The measurements were carried out with an ASC800 inverter and a 355-kW IM load machine, as shown in Fig. 17. The indirect water cooling consists of cooling ducts inside the frame of the radial flux machine. The cooling water input temperature varied in the range of $14{ }^{\circ} \mathrm{C}-16{ }^{\circ} \mathrm{C}$, and the flow rate was approximately $6.2 \mathrm{l} / \mathrm{min}$.

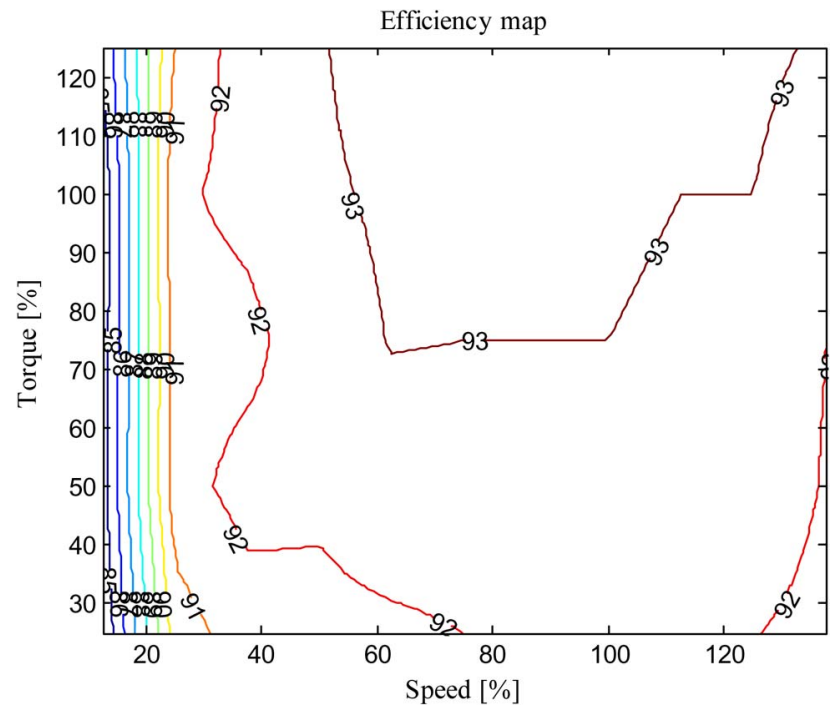

Fig. 19. Measured efficiencies as a function of torque and rotational speed.

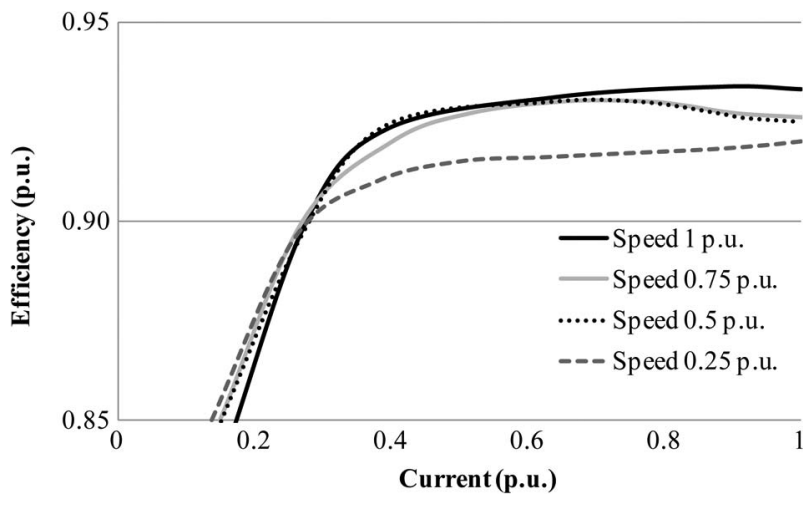

Fig. 20. Measured efficiencies with speed from 0.25 to 1 p.u. (rated current $143 A=1$ p.u.)

First, the induced voltages were measured, and the phase voltage waveforms are presented in Fig. 18. According to induced voltage measurements at $25{ }^{\circ} \mathrm{C}$ and $90{ }^{\circ} \mathrm{C}$ at end winding, it was estimated that at a rated situation $\left(120^{\circ} \mathrm{C}\right)$, the induced voltage RMS is $252.5 \mathrm{~V}$.

Next, the motor was warmed up to stable temperature, and after that, the output and input powers were measured. The input values were measured with a Yogokawa PZ4000 power analyzer, and the output values were measured utilizing a Magtrol torque transducer placed to shaft. An efficiency map for the designed 110-kW motor is depicted in Fig. 19. Correspondingly, Fig. 20. presents the measured efficiencies as a function of current with different speeds. It was expected that the measured efficiencies would be slightly higher; however, due to some inaccuracies in the manufacturing process, they were not achieved. The loss of efficiency was mainly caused by ferromagnetic material in the stator finger plates and a nonuniform air gap (a very small air gap at the other side of the machine) increasing pulsation losses significantly. This failure was caused by the stator yoke low height, which was not mechanically strong enough for the stack-fixing welding process. As a result, the inner race slightly deformed in the stack assembly process, and the outer and inner races of the 
TABLE IV

MACHINE Losses AT Nominal PoInT

\begin{tabular}{ccc}
\hline \hline Loss component & Calculated & Measured \\
\hline Copper losses [W] & 3000 & 3000 \\
Iron losses [W] & 1500 & $2100^{*}$ \\
Mechanical losses [W] & 400 & 800 \\
Total PM eddy current losses [W] & 300 & $300^{*}$ \\
Additional losses [W] & 400 & 900 \\
Total losses [W] & 5600 & 7000 \\
Efficiency & 0.95 & 0.932 \\
\hline \hline
\end{tabular}

* 2D computed and estimated based on previous knowledge

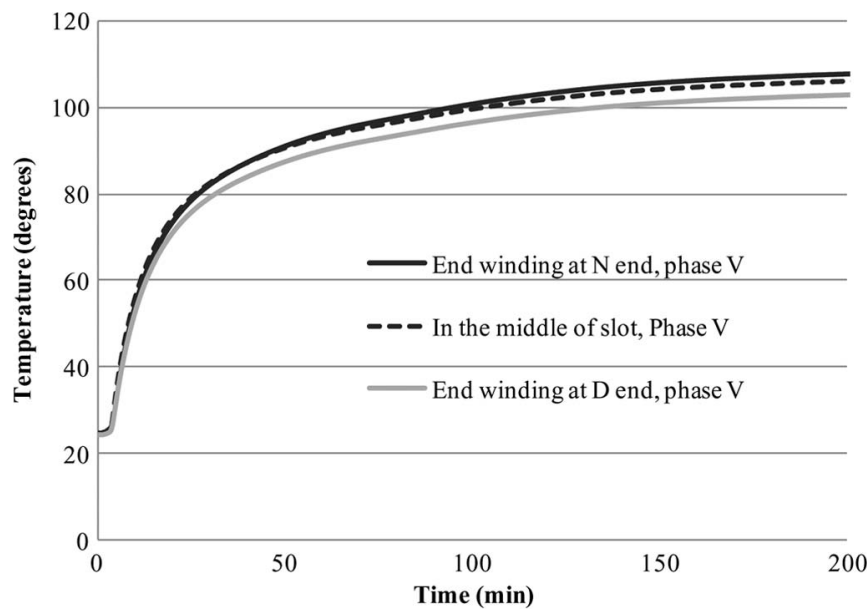

Fig. 21. Measured temperatures at a load of 0.8 p.u. and speed of 0.75 as a function of time.

stator stack were no longer perfect concentric circles. The overall losses in the finger plates, both in the rotor and stator, were calculated to be $900 \mathrm{~W}$, resulting in approximately $12 \%$ increase in the losses, which translates to $0.8 \%$ loss in the machine's efficiency.

Loss distribution at the nominal point is shown in Table IV in which the iron losses and PM losses are estimated from the 2-D FEA results. In [15] and [16], it has been verified by no-load measurements with and without magnets that the 2-D computed PM and iron losses correlate well with real measurement results. The no-load measurement gives the amount of mechanical losses + iron losses + PM losses.

Temperatures were measured with Pt-100 sensors. Temperatures of one phase (D-end, N-end, and in the middle of the slot) at 0.8-p.u. load and 0.75-p.u. speed are depicted in Fig. 21. One can see that $\mathrm{N}$-end has the highest temperatures; this is due to stator eccentricity at $\mathrm{N}$-end.

If prototype manufacturing had been carried out according to the design guidelines, the losses of the machine should have been significantly smaller. Indirect water cooling was also slightly insufficient for the high losses because the water channel width was too small- the end winding areas were not efficiently cooled. In addition, the control of the machine was not fully adjustable as we had to use a commercial industrial converter in the tests. If the advantage of the reluctance torque capabilities had been utilized better, the performance of the machine should have been slightly better. Better optimization between the reluctance torque and PM torque should be done

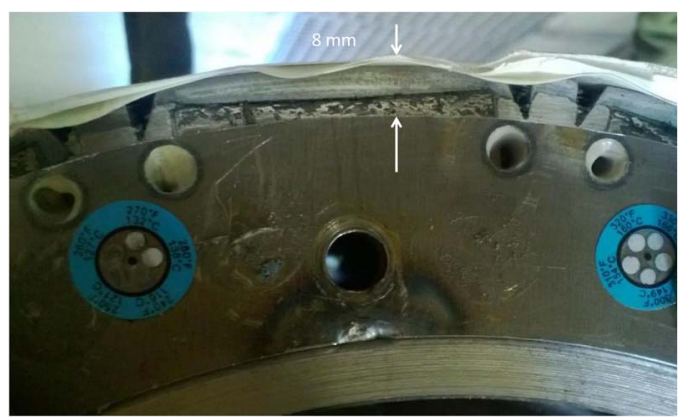

Fig. 22. Approximately $8 \mathrm{~mm}$ of the ferromagnetic end-plate material next to the permanent magnets was removed with a lathe. The permanent magnets are now partly seen in the rotor. The rotor also has a small iron part to increase the q-axis inductance.

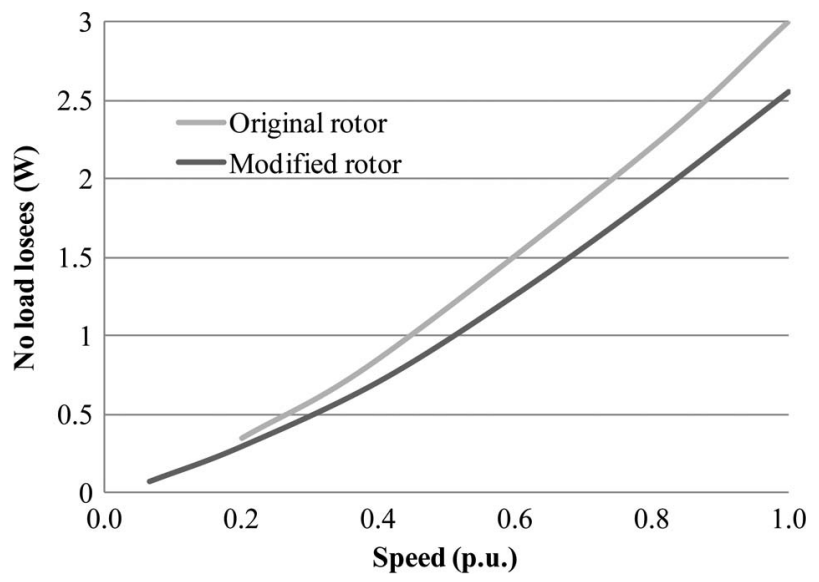

Fig. 23. No-load loss measurements with the original rotor and with the modified one (lower radius ferromagnetic end plates in the rotor).

to minimize PM material amount and cost. The main criterion in this study was not, however, the price but the performance of the machine. Despite the problems in the manufacturing, the machine efficiencies were, however, in an acceptable level.

After measurements, the rotor was removed, and it was modified, as presented in Fig. 22. Approximately $8 \mathrm{~mm}$ of the ferromagnetic end-plate material adjacent to the permanent magnets was removed with a lathe. The machining length was approximately $5 \mathrm{~mm}$ in the axial direction at both ends.

The no-load measurement was performed again, and one may see from the no-load measurement results in Fig. 23 that the noload losses decreased by $450 \mathrm{~W}$ with the improvements made in the practical realization of the rotor.

\section{CONCLUSION}

This paper has presented an example of the electromagnetic design process of a traction motor. The most important design boundaries for traction application are 1) the definition of the load cycle, 2) motor-cooling method capabilities, 3) supply unit resources, 4) supply-method-caused limitations, 5) torque demand at different operation points, and 6) price. Four different same-volume machines were analytically tested, and based on the optimization, one was selected to build the prototype. An optimization criterion was the amount of losses with 
different speeds. Calculation results were compared with the measured ones.

The manufactured and tested prototype machine did not achieve all the demands due to stator eccentricity and other manufacturing anomalies. The no-load measurement was performed with a modified (lower ferromagnetic end-plate radius) rotor, and the no-load losses were decreased by $450 \mathrm{~W}$. The prototype, however, proved that good efficiency and proper traction motor can be designed with tooth-coil windings and embedded permanent magnets.

\section{REFERENCES}

[1] L. Chong, R. Dutta, and M. F. Rahman, "Field weakening performance of a concentrated wound PM machine with rotor and magnet geometry variation," in Proc. IEEE PESC, Jul. 25-29, 2010, pp. 1-4.

[2] K. Kamiev, J. Montonen, M. P. Ragavendra, J. Pyrhönen, J. Tapia, and M. Niemelä, "Design principles of permanent magnet synchronous machines for parallel hybrid or traction applications," IEEE Trans. Ind. Electron., vol. 60, no. 11, pp. 4881-4890, Nov. 2013.

[3] P. B. Reddy, A. M. El-Refaie, K.-K. Huh, J. K. Tangudu, and T. M. Jahns, "Comparison of interior and surface PM machines equipped with fractional-slot concentrated windings for hybrid traction applications," IEEE Trans. Energy Convers., vol. 27, no. 3, pp. 593-602, Sep. 2012.

[4] G. Pellegrino, A. Vagati, P. Guglielmi, and B. Boazzo, "Performance comparison between surface-mounted and interior PM motor drives for electric vehicle application," IEEE Trans. Ind. Electron., vol. 59, no. 2, pp. 803-811, Feb. 2012.

[5] M. Barcaro, N. Bianchi, and F. Magnussen, "Permanent-magnet optimization in permanent-magnet-assisted synchronous reluctance motor for a wide constant-power speed range," IEEE Trans. Ind. Electron., vol. 59, no. 6, pp. 2495-2502, Jun. 2012.

[6] A. M. El-Refaie, "Fractional-slot concentrated-windings synchronous permanent magnet machines: Opportunities and challenges," IEEE Trans. Ind. Electron., vol. 57, no. 1, pp. 107-121, Jan. 2010.

[7] J. Nerg, M. Rilla, V. Ruuskanen, J. Pyrhönen, and S. Ruotsalainen, "Direct-driven interior permanent magnet synchronous motors for a full electric sports car," IEEE Trans. Ind. Electron., doi: 10.1109/ TIE.2013.2279126. [Online]. Available: http://ieeexplore.ieee.org

[8] P. Ponomarev, P. Lindh, and J. Pyrhönen, "Effect of slot and pole combination on the leakage inductance and the performance of tooth-coil permanent-magnet synchronous machines," IEEE Trans. Ind. Electron., vol. 60 , no. 10 , pp. 4310-4317, Oct. 2013.

[9] P. Salminen, T. Jokinen, and J. Pyrhönen, "The pull-out torque of fractional-slot PM-motors with concentrated winding," Proc. Inst. Elect. Eng._Elect. Power Appl., vol. 152, no. 6, pp. 1440-1444, Nov. 2005.

[10] J. Montonen, P. Lindh, and J. Pyrhönen, "Design process of traction motor having tooth-coil windings," in Proc. ICEM, Marseille, France, Sep. 2-5, 2012, pp. 1264-1268.

[11] J. Pyrhönen, T. Jokinen, and V. Hrabovcová, Design of Rotating Electrical Machines. Hoboken, NJ, USA: Wiley, 2008.

[12] J. Pyrhönen, V. Ruuskanen, J. Nerg, J. Puranen, and H. Jussila, "Permanent-magnet length effects in AC machines," IEEE Trans. Magn., vol. 46, no. 10, pp. 3783-3789, Oct. 2010.

[13] E. Fornasiero, N. Bianchi, and S. Bolognani, "Slot harmonic impact on rotor losses in fractional-slot permanent-magnet machines," IEEE Trans. Ind. Electron., vol. 59, no. 6, pp. 2557-2564, Jun. 2012.

[14] M. Barcaro, N. Bianchi, and F. Magnussen, "Remarks on torque estimation accuracy in fractional-slot permanent-magnet motors," IEEE Trans. Ind. Electron., vol. 59, no. 6, pp. 2565-2572, Jun. 2012.

[15] H. Jussila, "Concentrated winding multiphase permanent magnet machine design and electromagnetic properties-Case axial flux machine," Ph.D. dissertation, Lappeenranta Univ. Technol., Lappeenranta, Finland, 2009.

[16] J. Pyrhönen, H. Jussila, Y. Alexandrova, P. Rafajdus, and J. Nerg, "Harmonic loss calculation in rotor surface permanent magnets-New analytic approach," IEEE Trans. Magn., vol. 48, no. 8, pp. 2358-2366, Aug. 2012.

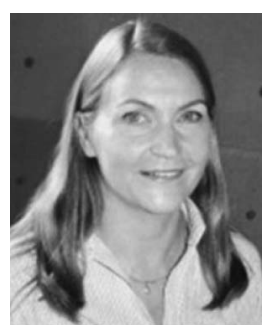

Pia Lindh (previously Salminen) (M'04) was born in Helsinki, Finland, in 1969. She received the M.Sc. degree in energy technology and the D.Sc. degree in electrical engineering (technology) from Lappeenranta University of Technology (LUT), Lappeenranta, Finland, in 1998 and 2004, respectively.

She is currently an Associate Professor with the Department of Electrical Engineering, LUT, where she is engaged in teaching and research on electric motors and electric drives. Her research work focuses on permanent-magnet motors, particularly concentrated winding machines.

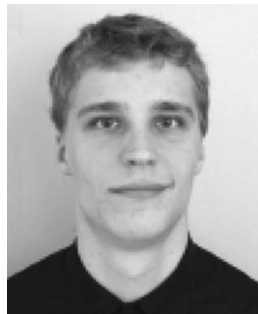

Juho Montonen was born in Joutseno, Finland, in 1988. He received the B.Sc. and M.Sc. degrees in 2011 and 2012, respectively, from Lappeenranta University of Technology, Lappeenranta, Finland, where he is currently working toward the Doctoral degree in the Department of Electrical Engineering.

His research work focuses on permanent-magnet motors, with a special focus on different kinds of traction applications. His research interests are in electrical machines and drives.

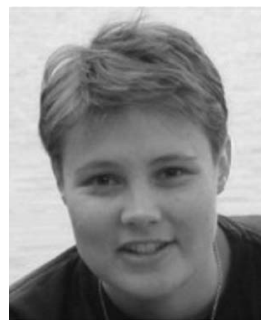

Paula Immonen was born in Imatra, Finland, in 1986. She received the Master's and D.Sc. degrees in electrical engineering from Lappeenranta University of Technology (LUT), Lappeenranta, Finland, in 2008 and 2013, respectively.

She is currently with the Department of Electrical Engineering, LUT. Her current research interest is in the diesel-electric hybrid drive system.

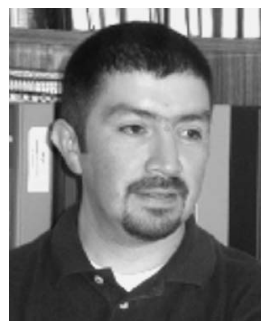

Juan A. Tapia (M'03) received the B.Sc. and M.Sc. degrees in electrical engineering from the University of Concepción, Concepción, Chile, in 1991 and 1997, respectively, and the Ph.D. degree from the University of Wisconsin, Madison, WI, USA, in 2002.

Since 1992, he has been with the Department of Electrical Engineering, University of Concepción, where he is currently an Associate Professor. His primary research areas are electrical machine design, numerical method for electromagnetic field, DSPbased electric machine control, and renewable energy.

Dr. Tapia has been a FiDiPro Fellow of the Academy of Finland at Lappeenranta University of Technology, Lappeenranta, Finland, since 2010, where he conducts research on permanent-magnet machines with the LUT Energia Group.

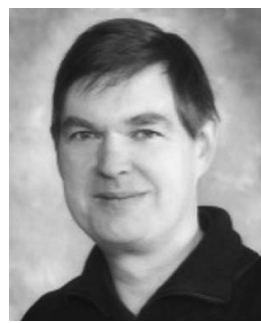

Juha Pyrhönen (M'06) was born in Kuusankoski, Finland, in 1957. He received the D.Sc. degree from Lappeenranta University of Technology (LUT), Lappeenranta, Finland, in 1991.

He became an Associate Professor of electrical engineering in 1993 and a Professor of electrical machines and drives in 1997 with LUT. He is currently the Head of the Department of Electrical Engineering, LUT, where he is engaged in research and development on electric motors and electric drives. His current interests include different synchronous machines and drives, induction motors and drives, and solid-rotor high-speed induction machines and drives. 